\title{
TI.80.1
}

\section{REN-ISAC and the Shared Darknet Project}

- PDF: 20060310_BU_Security_Camp_REN-ISAC.pdf

- Text: 20060310_BU_Security_Camp_REN-ISAC.txt

\begin{tabular}{|c|c|}
\hline \multicolumn{2}{|c|}{ More Information } \\
\hline Repository ID & TI.80.1 \\
\hline Persistent URL & http://doi.org/10.26869/TI.80.1 \\
\hline Title & REN-ISAC and the Shared Darknet Project \\
\hline Authors & Doug Pearson \\
\hline Sponsor & SALSA \\
\hline \multicolumn{2}{|l|}{ Review } \\
\hline Status & Legacy \\
\hline Publish Date & March, 2006 \\
\hline DOI & $10.26869 / T \mathrm{I} .80 .1$ \\
\hline \multicolumn{2}{|l|}{ Signature } \\
\hline Deprecated & No \\
\hline \multicolumn{2}{|l|}{ Future Review } \\
\hline \multicolumn{2}{|l|}{ Supersedes } \\
\hline Format & PDF, Text \\
\hline \multicolumn{2}{|l|}{ Related Docs } \\
\hline \multicolumn{2}{|l|}{ Development Location } \\
\hline \multicolumn{2}{|l|}{ IP Framework } \\
\hline Subject Tags & middlewarerescue \\
\hline Notes & \\
\hline
\end{tabular}

